\title{
Haemophilus aegyptius
}

National Cancer Institute

\section{Source}

National Cancer Institute. Haemophilus aegyptius. NCI Thesaurus. Code C86428.

A species of facultatively anaerobic, Gram negative, coccobacilli shaped bacteria assigned to the phylum Proteobacteria. This species is urease, catalase and oxidase positive, nonhemolytic and indole negative. $\mathrm{H}$. aegyptius is a pathogen and the causative agent of conjunctivitis and Brazilian purpuric fever. 